\section{SRC tries apprenticeship scheme}

DETAILED plans for two new experimental schemes aimed at improving the performance of graduates in industry are now being finalised by Britain's Science Research Council. The programmes, to be based on part-time studies, represent an unusual step by the normally academicallyorientated SRC and indicate a strong feeling that British industry in general makes poor use of its scientific and engineering intake.

Although many of the UK's larger companies have adequate training schemes for developing the industrial potential of new graduates, many smaller firms make two SRC projects aim to remedy the bias.

The first scheme, known as graduate initial education, will take the form of an apprenticeship package which will follow newly qualified students into industry. Through systems of tutorials, demonstrations and company-based projects over a two- or three-year period it will tailor their performance to the specific needs of their firms. A first experimental package, to cost about $£ 100,000$, is to be ready for student intake in October 1980 .

The second programme will consist of

technological topping-up education for graduates of about 10-year standing who require up-dated instruction on new industrial practices. This will include the many managers whose educations cover only transistor electronics and not modern microelectronics. The scheme will aim at familiarity with a basic working knowledge.

In both systems, universities will probably undertake instruction, and may even award degrees if it is thought the schemes would otherwise affect staffstudent ratios. However, in the case of the technological top-up programme, it is possible that the Open University, with its experience of popular presentation, may be introduced to instruct industrialists who might be alienated by a dry academic approach.

At the moment, both schemes are still at a rudimentary stage of planning and although they have been given the full goahead by the central council of the SRC, approval still has to be given by the Department of Education and Science as part-time higher education is not at present considered to be part of the council's remit. Fine-tuning for technology, page 352.

Robin McKie practically no arrangements for this. The

\section{Max Planck production venture fails}

"WE will concentrate future activities on our original function, which is to commercialise research results of the Max Planck Institute by licensing only," according to a spokesman of Garching Instrumente, a $100 \%$ commercial subsidiary of Max Planck Gesellschaft. The young enterprise has run into considerable difficulties, and finally has been forced to close down activities connected with the development and production of highly sophisiticated instruments and pilot equipment - activities that accounted for nearly three-quarters of Garching Instrumente's turnover and employment.

MPG established Garching Instrumente in 1970 as a limited liability company whose aim was to commercialise technically useful research results of the Max Planck Institute in the industrial field. Stimulated by successful American ventures of a similar kind (from which the un-German name "Instrumente" was borrowed) Garching Instrumente was not only to deal with licensing (especially of Max Planck Institute patents), but also with the development, production and distribution of high technology hardware.

From its beginning, the new company raised considerable hopes and expectations, for it was considered to be the prototype of the young, small high technology venture needed in West Germany. The importance attached to it can be deduced from the remarkable efforts of the Federal Ministry of Research and Technology in the early 1970 s to establish a risk financing corporation specifically to assist risky high technology ventures. least, Garching Instrumente seemed to fulfil the high expectations. Turnover increased to DM4 million with around 24 staff; among its clients were big companies like Siemens AG, as well as small enterprises, research institutes and universities. About $75 \%$ of the licence agreements were contracted with the instrument, electronics and pharmaceutical industries.

As time passed, however, it became increasingly obvious that research work on the one hand and manufacturing business on the other were very different, and that switching from one to the other is not easy. The activities of the manufacturing division of Garching Instrumente seemed to be less and less in line with the expectations of the Max Planck Gesellschaft, and there were rumours not only of management deficiencies but also of losses higher than could be tolerated even in a newly founded venture. Now, as a consequence, MPG has closed down all development and manufacturing activities, dismissed the management and reduced the staff to a mere handful. Activities are now restricted to licensing.

The new management looks optimistically to the future: "The actual turnover out of licence agreements already exceeds DM1 million. That brings us near the break-even point of our present activities."

Klaus Höpfner
In the first years of operation, at
Maurice Bazin reports from

Brazil on the return of the exiles for the country's major scientific conference

\section{Scientists protest at US tycoon's Amazonian project}

OVER 5000 scientists and social scientists congregated in the Brazilian north-east town of Fortaleza in mid-July for the 31st meeting of the SBPC, the Brazilian Society for the Progress of Science. The meeting's central theme was 'Dilemmas of Scientific Production in Brazil', reflecting the participants' preoccupation with the ways in which General President Figueiredo's Brazil is helping - or hindering - science. The problem of external dependency also lurked in the background as an everpresent spectre.

"The developed countries control science and technology, but they charge for letting us use it. And they charge dearly . . . . It is enough to see the chronic deficit of the Brazilian balance of payments. Part of this deficit comes from paying royalties and patent rights; these are, in the last analysis, the price we pay for scientific and technological dependence" read an official note distributed by the general secretariat of the SBPC on the opening day. This point came up at a round-table on 'National Scientific Policy' which involved three representatives of agencies financing scientific research in Brazil. Physics Professor José Leite Lopes, visiting his country after ten years of exile, declared: "It is useless to discuss a science policy without discussing the forces which oppose its formulation. Shall we discuss scientific policy without discussing economic policies?" He then added that nothing could be done as long as the economic forces representing the interests of multinational companies determine technological and scientific production in Brazil.

The president of the SBPC reminded everyone that the Brazilian scientific community was never consulted in the past about national projects, and it became evident during the meeting that academics were ready to take advantge of the recently granted freedom of expression to criticise strongly the government's options. The relaxed atmosphere of the meeting (where mornings were left free to allow participants to enjoy the town's beaches) was interrupted, however, when local police arrested five student participants for distributing "subversive material"; a federal security agent declared later that "in addition, they all had taken drugs".

The hottest discussions centred on two huge ongoing projects: the Jari agroindustrial project in the Amazonian jungle and the nuclear agreement with West 
Germany to build eight 1000 Megawatt nuclear plants in Brazil. Daniel Ludwig, an American citizen, owns a land area the size of Switzerland at the confluence of the river Jari and the Amazon. Investments in homogeneous forest plantation, a cellulose factory, cattle raising and rice growing on this site amount to $\$ 700$ million, and will reach $\$ 1.5$ billion in a few years when a paper factory is completed.

Banners reading "Amazonia is ours" were spread around an overflowing amphitheatre as Charles Briscoe, the American technician in charge of the Jari Project, explained that "Project Jari covers more than one million hectares in the State of Pará and the Federal Territory of Amapá . . . There are no boats loaded with gold or other riches leaving the country."' But critics pointed out that all of Jari's activities are geared exclusively for export, and that the appropriateness of their technology is never considered. Agricultural production, for example, is fully industrilized: rice is sown by plane and tree planting and cutting are fully mechanized. Parts of Briscoe's presentation met with boos from the participants, several of whom denounced foreign control and the elimination of the indigenous Indian population.

\section{West German nuclear deal heavily criticised}

The government's nuclear programme was strongly criticised by Brazilian physicists on economic and political grounds; the technical and environmental arguments which dominate the nuclear debate in industrialised countries were not brought up. Professor Luis Pinguelli Rosa of the Federal University of Rio de Janeiro proposed a drastic revision of the contract with West Germany. He claimed that Brazil is in a position of strength: "Germany presently does not have other clients for its reactors. The only reason we did not succeed in imposing our conditions is because we owe $\$ 40$ billion to the industrialised world, and that forces us to follow a policy which is perfect for our creditors but not for ourselves." $\mathrm{He}$ also indicated that an official report by the Ministry of Planning recognises that the cost of electrical energy produced by nuclear reactors is three times that from hydroelectric schemes.

A longer-term view was presented by Professor Mario Schemberg, who trained some of the best known Brazilian physicists before he was forcibly ietired from the University of Sao Paulo by the military government in 1969. He made an appeal for "freeing ourselves from the useless weight of the nuclear agreement with Germany, and cancelling the pledges which the military dictatorship made without consulting the people." He proposed an energy programme for Brazil for the next fifty years which would emphasise research in solar energy and nuclear fusion.

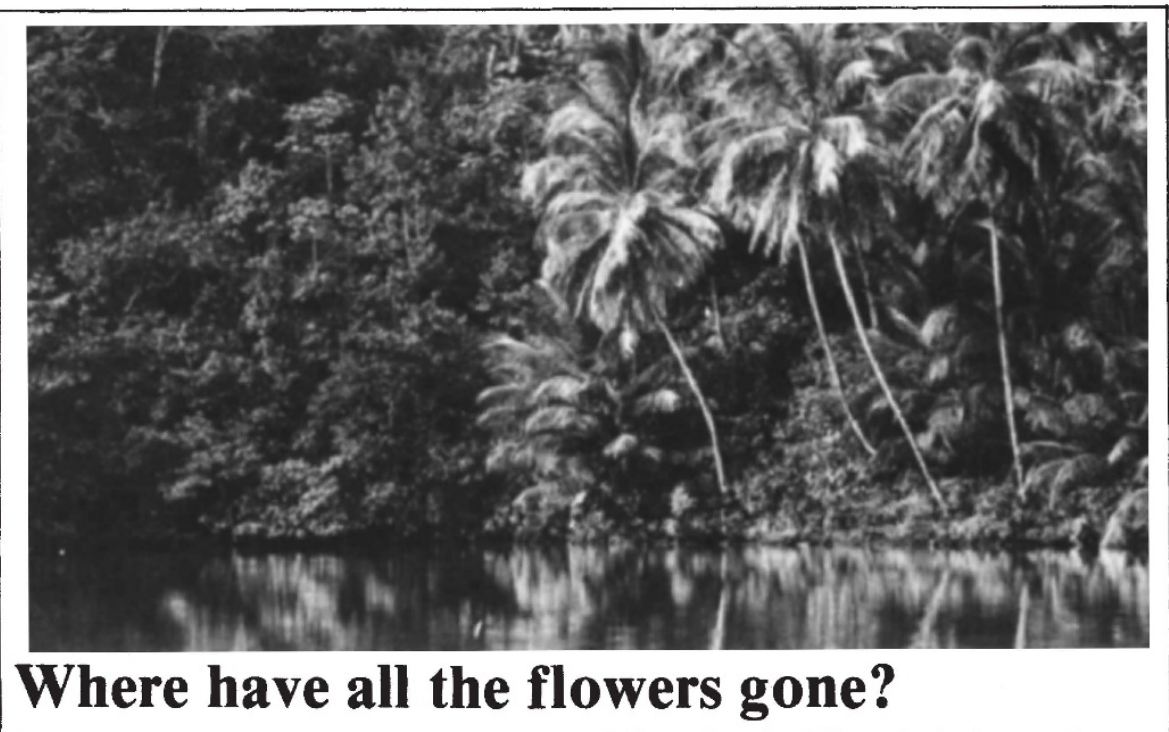

THE savage destruction of the Brazilian rain forests has been dictated, to a large extent, by economic pressures over which the country's government can exercise little control. Yet this rapidly dwindling heritage of exotic plants and animals kindled the imagination of early explorers and continues to contribute to our understanding of our natural environment. In Brazil today the cultural and economic influence of the West is very apparent, and so it is strange to find little native interest in natural history reflected on the shelves of the big bookshops of cities such as Rio de Janeiro, Brasilia and Belo Horizonte. Despite a good deal of enquiry the only books I could find dealing with Brazilian wildlife at all were translations of glossy foreign 'coffee table' volumes.

Long searches through the second-hand markets uncovered only four more: a series published in Säo Paulo in the 1950s dealing with insects, birds and mammals; and a magnificent translation of an illustrated French book on Amazonian primates, published at the turn of the century whose value was, unfortunately, well appreciated by the dealer. The Brazilian flora suffer a similar neglect, even though, at certain times of the year, one would be well advised to take some sort of field guide along when visiting the local fruit and vegetable markets.

Being able to name and classify species of plant and animal is an essential cornerstone of biological science and education. Once these basic elements can be identified, and their interactions understood, one may begin to appreciate the fragility of eco-systems such as the tropical rain forest.

It is disturbing, therefore, to find that wouldbe medical students, when asked to give the names of all the animal species they knew, could list, on average, only half a dozen - invariably creatures of medical importance such as the mosquito, the cockroach and the 'barbeiro', the bug vector of Chagas disease. Although this survey carried out by Professor Angelo Machado of the Federal University of
Minas Gerais, did not include questions on plant life, my own experiences suggested that here the situation is even worse. Indeed, one graduate biologist I spoke to was surprised to discover that naturaI selection occurs outside the animal kingdom!

Machado is a well respected morphologist and neuroanatomist, whose spare time pursuits include some most elegant studies on the ecology and taxonomy of neo-tropical dragonflies. His wide interests include conservation - he is a founder member of one of the few environmental pressure groups in the country - and, more recently, an attempt to understand the lack of interest in wildlife which is apparent in the country's development of its natural resources. Brazil's politicians and administrators, he feels, are 'frightened by nature', and so he has turned to studying the development of the concept of the 'forest' in school children throughout the country.

This survey is still in its early stages, but Machado has already found that the child's concept of the forest, and its association with fear, begins to form early in life. It seems to be based on nursery rhymes and children's stories imported from Europe and North America, which emphasise the dangers of going into the woods.

In the younger child this ignorance can be easily counteracted. Drawings and paintings of the 'forest' made by 7-10 year olds commonly included aeroplanes spraying the undergrowth with bullets and napalm; but after the same children had been taken by Machado on a trip to the real forest these were replaced by birds and butterflies, and the children paid far more artistic attention to leaf forms and flowers.

At the present rate of development Brazil's forests may only survive for another 30 years, but if Machado's children can be so easily convinced of its value there is some hope that this new generation may allow it to stand for longer. The final decision may perhaps lie with the teachers rather than the politicians.

David Bousfield 